\title{
Cultura Científico-Tecnológica na Educação Básica
}

\author{
Carlos Alberto Souza \\ Universidade Federal de Santa Catarina, Colégio Agrícola de Camboriú, Programa de \\ Pós-Graduação em Educação Científica e Tecnológica, Rua João da Costa, s/n, CX. P. 16, \\ Centro, Camboriú, SC, Brasil, \\ CEP: 88340-000, Fone 47 3365-1055,e-mail: carlosal@ced.ufsc.br \\ Fábio da Purificação de Bastos \\ Universidade Federal de Santa Maria, Programa de Pós-Graduação em Educação, \\ Campus Universitário, Bairro Camobi, Santa Maria, RS, Brasil, \\ CEP: 97119-900, Fone(fax) 55 2208010,e-mail: fbastos@ce.ufsm.br \\ José André Peres Angotti \\ Universidade Federal de Santa Catarina, Programa de Pós-Graduação em Educação, \\ Campus Universitário, CX. P. 476, Bairro Trindade, Florianópolis, SC, Brasil, \\ CEP: 88010-970, Fone 48 3318706, e-mail: angotti@ced.ufsc.br
}

\section{Resumo}

Apesar de a sociedade estar permeada pelos conhecimentos científicotecnológicos, reconhecemos seu distanciamento da cultura das pessoas em geral, inclusive daqueles que concluem a escolaridade básica neste país. Há um convívio cotidiano com o desconhecido. Apesar das políticas públicas contemplarem avanços na melhoria da escolaridade básica, afirmamos que ainda precisamos agir para aproximar os conhecimentos científico-tecnológicos da sala de aula. Os próprios currículos não reconhecem o potencial dos Meios Tecnológico-Comunicativos nas práticas escolares. Minimizar esta situação, incorporando estes recursos no trabalho pedagógico, pode favorecer a inclusão que deve ser um compromisso político dos educadores.

Palavras-chave: conhecimentos científico-tecnológicos; meios tecnológicocomunicativos; cultura.

\section{Abstract}

Although the society has lots of Scientific and Technological knowledge, it is seen as something far from the culture of people, including from those ones who can finish basic school in this country. There is an everyday life with the unknown. In spite of the public policies have noticed some improvement in this direction, it is a statement the necessity to face this distance in the classroom. The résumés do not recognize the potential of the Technological and Communicative Means in the school practicing. To minimize this situation by joining these resources in the pedagogical work, can benefit the inclusion, as it must be a commitment among the teachers. 
Key-word: scientific and technological knowledge; technological and communicative means; culture.

\section{Cultura Científico-Tecnológica: sempre exclusividade de alguns?}

A atividade desenvolvida pelos cientistas, que vivem uma cultura científicotecnológica, é pouco compreendida pela maioria das pessoas. A presença dos objetos tecnológicos na vida das pessoas não significa que eles façam parte de sua cultura. Vê-los e usá-los não significa compreender a ciência e a tecnologia envolvida em sua fabricação e funcionamento.

Para Bazin (1998), uma sociedade pode ser tecnologizada mesmo que as tecnologias não façam parte da cultura das pessoas. Não é difícil entender que o fato de as pessoas utilizarem torneiras com sensor ótico, receberem multas pelos radares nas estradas, retirarem extratos e fazerem saques nos caixas eletrônicos, efetuarem pagamentos ou aguardarem a porta do banco e se posicionarem para ter acesso a ele, não significa que compreendem o seu funcionamento.

Para os que produzem tais bens de consumo, o objeto deve ser, ao mesmo tempo, de fácil uso e funcionar como uma "caixa preta". Os objetos tecnológicos estão cada dia mais vedados e impenetráveis. Concordamos com Bazin (1998) quando afirma que isso tem dificultado a entrada dos conhecimentos tecnológicos na cultura geral. Aliás, "o problema social da ciência é justamente não estar NA cultura" (BAZIN, 1998, p. 30). É muito diferente do que consegue o esporte, a música ou mesmo a religião, aponta o autor.

As pessoas têm algo a dizer sobre questões relacionadas ao futebol, à religião e a tantos outros assuntos que se fazem presentes no nosso dia-a-dia. Por outro lado, quando questionadas a respeito de algo relacionado à ciência e tecnologia, as pessoas não se envergonham em dizer o quanto desconhecem o assunto. A pior situação vivida é quando as pessoas afirmam que isso é assunto para o 'povo da ciência'.

Muitas vezes, quem desconhece a capital de um país ou estado é olhado com desconfiança pelos colegas. Desconhecimento observado como falta de cultura. Por que

\footnotetext{
${ }^{1}$ Ver p. 8 deste artigo.
} 
isso não ocorre no âmbito da ciência e tecnologia? Nesse campo, a normalidade parece ser o desconhecimento. Na escola, há quem diz não saber nada de Física e que só fazia o necessário para se livrar dessa disciplina. Nossa preocupação aumenta quando, não raro, esse comentário tem origem nos próprios professores de ciências. Afinal, qual o nosso papel como professores de Física nessas situações? Temos contribuído para (romper) a distância existente entre a ciência e a tecnologia de nossa cultura?

As políticas públicas educacionais caminham para mudar essa situação, mas é preciso perceber seu distanciamento nas aulas. Os currículos escolares pouco potencializam os Meios Tecnológico-Comunicativos (MTC) ${ }^{2}$ nas práticas escolares. Incorporar essa cultura significa agir efetivamente mediado pelos MTC. Problematizar, incorporando os MTC em nossas práticas escolares, é também um compromisso políticopedagógico, pois negligenciá-los é reforçar a exclusão sócio-educacional.

A educação científico-tecnológica não é somente um componente. A dimensão cultural dessa ação bem como a percepção sobre a sociedade e o cidadão e o seu lugar nela, recoloca o ensino médio na vida dos cidadãos. Principalmente, porque a grande maioria não tem chegado ao ensino superior. Mesmo para os que seguem, uma minoria terá oportunidade de estudar Ciências da Natureza, Matemática e suas Tecnologias (CNMT). Mesmo reconhecendo que os MTC não se restringem a essa área, não podemos desconsiderar a responsabilidade que as CNMT possuem com a formação escolar.

Talvez os próprios livros didáticos e os de divulgação tenham contribuído para a não inserção da ciência e tecnologia na cultura. Algo muito distante da vida das pessoas, das observações cotidianas. Até o século XVIII, período considerado por Bachelard (1996) como pré-científico, o livro tinha como ponto de partida a natureza, a vida cotidiana. Havia preocupação com a divulgação científica, em levar o conhecimento às pessoas, que poderiam debatê-los.

O livro possui um papel fundamental no processo educacional para Bachelard (1996). É ele quem veicula a ciência na sociedade. Hoje, também podemos contar com os

\footnotetext{
${ }^{2}$ Entendemos por MTC em educação aqueles meios que estão relacionados à mediação computadorizada, em rede, informatizada, abrigando hipermídia, multimídia, ferramentas essenciais da educação à distância (salas de discussão, fóruns, correio eletrônico, por exemplo) e outros recursos digitais que podem colaborar para melhorar o processo escolar. São meios das tecnologias da informação e comunicação (PARENTE, 1993).
} 
livros virtuais na internet que potencializam a difusão. Porém, é preciso cautela quando acessamos a internet, pois nem todas as informações possuem boa confiabilidade. Destacamos a contribuição do MEC para avaliar e investir nos livros didáticos. A partir desse trabalho, reconhecemos que este cenário tem melhorado e podemos contar com bons referenciais didáticos.

Uma escola fechada aos conhecimentos dos nossos dias, à produção da ciência e tecnologia, é a própria negação do que denominamos de cultura científico-tecnológica. A escola precisa trabalhar e responsabilizar-se por essa cultura. Dos componentes estruturais de nossa cultura, a ciência e a tecnologia têm papel de destaque, merecendo aprofundamento no ensino médio, seja pelo seu viés técnico-prático ou seu sentido cosmológico, como visão de mundo.

\section{O conhecimento científico-tecnológico integrado à cultura: o papel do currículo}

Aprender CNMT envolve a iniciação dos alunos em uma nova maneira de pensar e explicar os mundos natural e tecnológico, que é fundamentalmente diferente daquelas disponíveis no senso-comum. Isso envolve um processo de socialização das práticas da comunidade científica e de suas formas particulares de pensar e ver o mundo, em última análise, um processo de 'enculturação'.

Aprendemos quando ultrapassamos a fase da repetição e estabelecemos nossas próprias relações com o objeto do conhecimento. Trata-se de construção contínua porque não paramos de formar novas estruturas quando aprendemos. Nesse processo de aprender, o ser humano modifica o mundo e é modificado por ele. Daí que o ensino precisa priorizar atividade, argumentação e trabalhos colaborativos. Portanto, nosso objetivo é formar o pensamento crítico, autônomo, criativo.

A necessidade de uma reformulação do ensino de CNMT nessa direção nos parece urgente. Isso porque ${ }^{3}$

Se formos além dos programas escolares até as realidades psicológicas, compreenderemos que o ensino de ciências tem de ser todo revisto; que as sociedades modernas não parecem ter integrado a ciência na cultura geral. A desculpa dada é que a ciência é difícil e que as ciências se especializam.

\footnotetext{
${ }^{3}$ É importante ressaltar que a mudança de época e de lugar não retira a contemporaneidade da crítica de Bachelard.
} 
Mas, quanto mais difícil é uma obra, mais educativa ela será. Quanto mais uma ciência é especial, mais concentração espiritual ela exige (BACHELARD, 1996, p. 309, grifos nossos).

Como afirma Zanetic (2002), mesmo reconhecendo avanços na pesquisa em Ensino de Física, o século XX já terminou e a Física Moderna e Contemporânea que se desenvolveu nele, em sua grande maioria, ainda não está contemplada nos currículos no ensino médio. Na cultura científico-tecnológica não podemos deixar de perceber "o quanto ainda temos de caminhar para marcar uma forte presença da Física na formação do homem contemporâneo e do homem do futuro. Enfim, olhando para o futuro, deparamonos com inúmeros desafios para o ensino de Física" (ZANETIC, 2002, p. 2). Apesar dos avanços conquistados com o desenvolvimento das Pesquisas em Ensino de Física, assumimos que a cultura científico-tecnológica ainda é muito restrita.

Maia Vidal (2002) destaca que o Subprograma Educação para a Ciência (SPEC) incentivou a procura e a implantação de novas estratégias e a consolidação de iniciativas existentes e comprovadamente eficientes, visando à melhoria do ensino de Ciências e Matemática no País (PADCT, 1984). As contribuições das diversas pesquisas demonstraram que a inserção da educação científico-tecnológica no currículo escolar encontrou dificuldades, pois uma proposta de mudança curricular demanda um conjunto de ações correlatas dirigidas para e pelos sujeitos educacionais. Apesar dos Parâmetros Curriculares Nacionais introduzirem uma nova proposta para o ensino de CNMT, ainda falta entendimento dos professores quanto às inovações.

Não se trata, então, como afirma Postman (1994), da cultura se render à tecnologia, mas de construirmos uma cultura no âmbito da ciência e da tecnologia. Uma cultura com uma boa base moral e ética. Afinal, se por um lado a tecnologia pode ser utilizada para fazer o mal, por outro podemos apontar inúmeros exemplos de situações que nos favorecem para que possamos ter uma vida melhor. Quem não gosta de conversar com uma pessoa querida por telefone? Antes do telégrafo a notícia era transmitida com a velocidade do trem. Trem que também é uma produção da tecnologia! Quem se atreveria a fazer, hoje, uma viagem que não fosse pelo menos de automóvel? Quem, após ter experimentado os benefícios da energia elétrica, pode optar, na esfera da consciência, por não tê-la em sua casa? Quem, mesmo não tendo, despreza refrigerador e fogão a gás? 
Afirmar que "as escolas ensinam seus filhos a operar sistemas computadorizados, em vez de ensinar coisas mais valiosas para as crianças" (POSTMAN, 1994, p. 20) não nos auxilia muito. Não concordamos com a expressão em vez de, pois uma coisa não exclui a outra. Se a escola deixa de cumprir seu papel nessa perspectiva, não significa que precisa falhar em outra. Também não afirmaríamos que "para os perdedores não acontece quase nada do que precisam" (POSTMAN, 1994, p. 20), pois preferimos interpretar como sujeitos incluídos e excluídos. Se pensarmos em torno da cultura científico-tecnológica, tratar-se-ia de incluir os excluídos. Apesar dos benefícios da tecnologia se espalharem, não significa que isso ocorra por igual. Por que isso ocorreria em uma sociedade tão desigual? Não podemos exigir que as tecnologias tenham o poder de corrigir o mundo.

Fourez (1997, p. 81) também contribui para com essa discussão questionando o que é necessário para ser educado científico-tecnologicamente. Para ele, temos razões humanistas ou da autonomia do indivíduo e suas possibilidades para atuar e se comunicar. Nessa direção, Fourez (1997) destaca alguns critérios: primeiro, é importante saber dialogar com os especialistas "como decidir, por exemplo, se é preciso buscar uma segunda opinião? Como saber quando é sensato transgredir sua opinião?” (p. 64); segundo, vincula-se a mediação das caixas-pretas, sendo que "todo processo científico ou racional utiliza o que os físicos designam de caixa-preta" (p. 65). Afinal, "saber quando e como é interessante ou não abrir uma caixa-preta (ou seja, aprofundar certas noções em certos contextos e no quadro de certos projetos) é essencial à alfabetização científicotecnológica" (p. 65-6).

Entendemos que cabe ao professor (detentor do novo espírito científico, investigador da própria prática docente), a decisão de quando deixar fechada ou abrir uma caixa-preta; terceiro, está relacionado à abertura das caixas-pretas "se se trata de construir modelos simples, mas pertinentes para certo contexto, evitando confundir-se em teorizações inúteis para a situação precisa, sem dúvida, sem hesitar, em aprofundar o que, precisamente para o caso, o mereça" (p. 67); quarto; o uso e invenção de modelos interdisciplinares, cruzando saberes de diversas disciplinas e conhecimentos da vida cotidiana, para estruturar um modelo ou teorização dentro de um contexto, capaz de solucionar um problema. 
Assim, desenvolve o conceito de ilha de racionalidade que "designa uma representação teórica apropriada a um contexto e a um projeto que se tem em perspectiva e que permite comunicar-se e agir com referência ao mesmo tempo em que se refere a contexto e a projeto particulares, diante dos quais se acha interessante construir uma representação" (p. 69); sexto, refere-se ao uso das metáforas ou comparações, pois é preciso ensinar os jovens a desconfiar das imagens e a utilizar somente conceitos verdadeiramente científicos. As metáforas são apontadas como obstáculo epistemológico bachelardiano e necessitam de boa utilização na educação científico-tecnológica; sétimo, aponta o bom uso da negociação, pois "as práticas científicas e as técnicas são o produto de negociações" (p. 74); oitavo, o bom uso da articulação entre saberes e decisões, "sem desvalorizar a importância cultural de nossos saberes, é necessário também podê-los utilizar na existência concreta” (p. 75); finalmente, Fourez (1997) aponta o bom uso dos debates técnicos, éticos e políticos, "estar alfabetizado científico-tecnologicamente implica a capacidade de não confundir esses três debates e, sobretudo, de evitar crer que se pode sempre substituir as deliberações éticas e políticas por reflexões técnicas" (p. 76), o que se configuraria como uma cultura tecnocrática.

Dessa forma, corroboramos a conclusão do autor de que os professores de CNMT precisam desenvolver em sua prática escolar a cultura científico-tecnológica. Isso significa passar por um ensino contextualizado e não como uma verdade com fim em si mesmo. Portanto, "que se terá consciência de que as teorias e modelos científicos não são bem compreendidos se não se capta por que, em vista de que e para quem se tem inventado" (p. 81, grifos do autor).

Preferimos a idéia de cultura à de alfabetização. Preferimos trabalhar na perspectiva de viver essa cultura cotidianamente, pois o processo educacional não é, nem pode, dar-se por acabado, pronto. Até porque as descobertas e criações ocorrem com uma velocidade muito grande e alguém que se considera educado científico-tecnologicamente precisa viver essa cultura.

\section{Alguns desafios necessários para a prática escolar}

É preciso acreditar que o aluno é capaz de assumir atitudes de respeito e diálogo, desenvolvendo habilidades para trabalhar com conceitos que a grande maioria das 
pessoas não domina. Esse é o ponto de partida do trabalho escolar que desenvolvemos (Souza, 2004). Desafiamos o grupo - alunos e/ou docentes - a pensar as suas ações escolares, revelando valores e a necessidade de superar práticas que, desveladas, se mostram frágeis para solucionar situações-problema da realidade.

Para Bachelard (1996), é no movimento de ensinar-aprender conhecimentos que o pensamento se vitaliza. Há a formação de espíritos dinâmicos e autocríticos, nos quais o conceito é obtido por racionalização. Por isso, ensinar é a melhor maneira de aprender, de perceber o que não sabemos. É assim que se constata o empreendimento da dialogicidade.

A aprendizagem não começa, mas continua; supera um conhecimento para construir outro, mesmo que o velho continue convivendo no novo Bachelard (1996). Ele ressalta que precisamos estar atentos aos erros e à noção de superação, reconhecendo duas grandes ilusões: o continuísmo dos conhecimentos comum e científico e a crença de se partir do nada. A educação científico-tecnológica necessita romper definitivamente com a "pedagogia bancária" (FREIRE, 1985), de transmissão-recepção, memorização de informações e conhecimentos, e passar a se fundamentar na mediação dos MTC como ferramentas do fazer-pensar, para a resolução de problemas (RP) do seu meio social, de forma dinâmica e criativa, seja individualmente ou em grupos, de forma colaborativa.

Apontar limites e dificuldades juntamente com soluções e melhoria da prática escolar, valorizar o fazer-pensar e, com ela, caminhar para um distanciamento dos hábitos de repetição e de memorização, assim vamos formando o espírito científico nos movimentos ação-reflexão-ação e concreto-abstrato-concreto. O ensino mediado por objetos tecnológicos do concreto permite esse movimento, transitando entre o sensocomum e o aprender ciência e tecnologia.

Compreensão não é algo que se transmita. Pode ser conseguida com esforço e participação de quem aprende. Conhecer significa também transformar o objeto do conhecimento. Nesse sentido, os erros não são acidentes de percurso, que desaparecem por si mesmos na medida em que o sujeito vai compreendendo. Eles têm um papel constitutivo no ato de conhecer. Eles expressam determinadas relações, pré-concepções já existentes. Devem ser explorados, expostos, discutidos. E o que se chama de 
metacognição ${ }^{4}$ é a atenção que o sujeito cognitivo deve dar às formas como vivencia a aprendizagem nos seus avanços e retrocessos.

Com os MTC podemos incrementar o ensinar e aprender, tanto presencial como à distância, abrindo espaço para a investigação-ação nas aulas. As aulas podem constituirse num processo contínuo de estudo, comunicação e investigação.

É importante que saibamos formular problemas, porque eles não se apresentam por si mesmos. Esse sentido do problema é que dá a característica do espírito científico ${ }^{5}$. Será que a aula é exclusividade da teoria? Será que o professor encontra possibilidade de formação de espíritos dinâmicos e autocríticos?

A prática escolar precisa possuir uma dimensão investigativa, compreendida por nós como o novo espírito científico a ser desenvolvido, e constitui uma forma de criação ou, pelo menos, recriação do conhecimento. A participação na construção de um projeto pedagógico de curso, por exemplo, implica atividades investigativas ${ }^{6}$ que precisam ser valorizadas. Assim, o espírito científico não pode contentar-se em apenas refletir sobre a prática escolar (uma das etapas da investigação-ação), mas em analisar planejamentos e registros. Aproxima-se o real, retomando seu lugar no re-planejamento, alargando o pensamento do investigador ativo.

Para Freire (1999), a matriz do pensar ingênuo ou crítico é a mesma: a curiosidade. Então, ressalta que precisamos possibilitar que a curiosidade ingênua, voltando-se sobre si mesma, por meio da reflexão na prática, perceba-se como tal e_vá se tornando crítica. "Por isso é que, na formação permanente dos professores, o momento fundamental é o da reflexão crítica sobre a prática. É pensando criticamente a prática de hoje que se pode melhorar a próxima prática" (FREIRE, 1999, p. 43-44, grifos nossos). Análise crítica não é privilégio de alguns, não é um bem que se recebe de alguém. É o processo de reflexão que nos torna críticos. O que nos autoriza dizer que "quanto mais me assumo como estou sendo e percebo a ou as razões de ser de

\footnotetext{
${ }^{4}$ Segundo Flavell (1976), a metacognição se refere ao conhecimento do sujeito sobre seus próprios processos cognitivos e o seu produto.

5 Um conjunto de hábitos, de pensamentos, atitudes, valores e interesses constituem a matriz que fundamenta psicologicamente a construção do conhecimento científico.

${ }^{6}$ Entendemos por atividades investigativas aquelas decorrentes de processos de investigação-ação escolar situados no movimento cíclico-espiralado que a caracterizam.
} 
porque estou sendo assim, mais me torno capaz de mudar, de promover-me, no caso, do estado de curiosidade ingênua para o de curiosidade epistemológica" (FREIRE, 1999, p. 44, grifos nossos).

A não valorização da prática investigativa-ativa reforça a visão dicotômica entre teoria e prática e distancia o sujeito da possibilidade de problematizar a prática escolar. Logo, não percebe a dimensão criativa que emerge da prática, não estimulando o "consumo" dos produtos da pesquisa. Com isso, a familiaridade com os procedimentos científicos e com o processo histórico de produção e disseminação de conhecimento é apenas um item a mais. Isso limita a processualidade de produção e apropriação de conhecimento e da provisoriedade das certezas científicas.

Desafiados por situações-problema, que exigem superação e experiências em situações didáticas, podemos refletir, experimentar e agir, a partir dos conhecimentos científico-tecnológicos. A perspectiva da educação científico-tecnológica é desenvolvida ao propormos desafios iniciais aos alunos. Não questionamos nominalisticamente a rede conceitual aprendida nas disciplinas de CNMT, mas sim sua operacionalização numa determinada situação-problema colocada. Por exemplo, como funciona o "pardal" que registra o excesso de velocidade dos carros?

A partir desse momento inicial, sugerem-se leituras problematizadoras, agora mais específicos e acoplados aos princípios científico-tecnológicos que sustentam os referidos funcionamentos. Problematizamos não apenas o caráter científico-tecnológico do referido equipamento tecnológico, mas seus aspectos sociais, históricos e educacionais. Esse trabalho educacional dialógico-problematizador (SOUZA, 2004) é composto por leituras, RP, organização de estratégias didático-metodológicas, atividades de ensino de ciência e tecnologia experimentais.

Assumimos na prática escolar as Diretrizes Curriculares Nacionais para a Formação de Professores da Educação Básica, em especial

As competências referentes ao comprometimento com os valores inspiradores da sociedade democrática; as competências referentes à compreensão do papel social da escola; as competências referentes ao domínio dos conteúdos a serem socializados, aos seus significados em diferentes contextos e sua articulação interdisciplinar; as competências referentes ao domínio do 


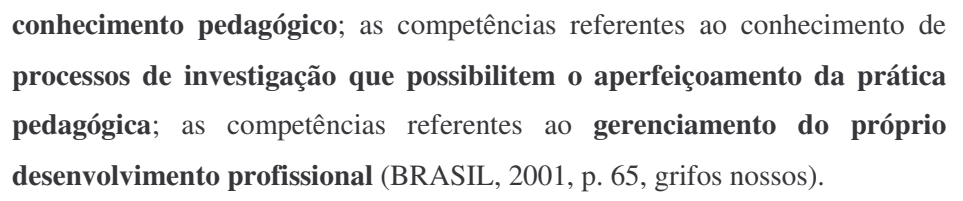

Admitimos ser fundamental o exercício dos processos de investigação que possibilitem o aperfeiçoamento da prática pedagógica. Da mesma forma, acreditamos que para o investigador ativo "o espírito científico deve formar-se enquanto se reforma" (BACHELARD, 1996, p. 29). Uma possibilidade, segundo as qualidades destacadas acima, pode ser potencializada nas situações que estimulam a reflexão nas ações pedagógicas. Para que se modifique é necessário "que os leve a rever sua prática sobre o que é e como ensinar seus alunos" (BRASIL, 1999b, p.159).

Para nós, trata-se de ensino-investigação-aprendizagem, exigindo reflexão crítica na prática, rigorosidade metódica que caracteriza, segundo Freire (1999), a curiosidade epistemológica do sujeito. Essa superação pode ser atingida com a colaboração entre aluno e professor. Precisamos possibilitar por meio da reflexão na/sobre a prática, que a curiosidade ingênua, percebida como tal, vá tornando-se crítica.

Compreendida dessa forma, percebemos que a investigação-ação é desenvolvimento profissional dos investigadores ativos. Necessita de um processo de reflexão colaborativa, enfoca análise conjunta de meios e fins na prática, propõe mudança das realidade e prática escolares mediante a compreensão prévia e colaboração dos investigadores ativos nos planejamento, desenvolvimento e estratégias de mudanças. Resumindo, é o ensino-investigação-aprendizagem baseado na compreensão da aula.

Os trabalhos desenvolvidos na área educacional têm apontado para atuações no campo da investigação ligada à prática, investigação-ação, ação reflexiva e investigação qualitativa. Antolin (1996) aponta que essa é a tendência mundial das investigações escolares, fortalecendo a integração entre investigação e ação educativas durante a escolarização.

Consideramos que a inserção do componente investigativo na escolarização científico-tecnológica é prioritária para a cidadania. Isso porque ensinar, para nós, significa dialogar e problematizar situações-problema mediados por conhecimentos dessa 
natureza. Para tanto, temos apontado a necessidade da mediação dos MTC para essa organização.

O investigador ativo incorpora essa cultura ao processo de ensino-investigaçãoaprendizagem, buscando soluções para os problemas da prática escolar, valorizando comunicação e ensino-investigativo, modificando o vigente, tradicional. Novas possibilidades didáticas se apresentam na direção do fazer-pensar.

\section{REFERENCIAS:}

ANTOLIN, V. B. La Didáctica como espacio y área de conocimiento: fundamentación teórica e investigación didáctica. In: ENDIPE - ENCONTRO NACIONAL DE DIDÁTICA E PESQUISA EM ENSINO, 8, Florianópolis, 1996. Anais do VIII Encontro Nacional de Didática e Pesquisa em Ensino. vol. 2, Florianópolis: NUP/CED, 1996.

BACHELARD, G. A Formação do Espírito Científico: contribuição para uma psicanálise do conhecimento. Tradução Estela dos Santos Abreu. Rio de Janeiro: Contraponto, 1996. 314p. Título Original: La formation de l'esprit scientifique: contribution a une psychanalyse de la connaissance.

BAZIN, M. Ciência na nossa cultura? Uma práxis de educação em ciências e matemática: oficinas participativas. Revista Educar: ed. Da UFPR, Curitiba, n. 14, 1998, p. 27-38.

BRASIL. Ministério da Educação. Diretrizes Curriculares Nacionais para a Formação de Professores da Educação Básica, em nível superior, curso de licenciatura, de graduação plena. Brasília: MEC, 2001. (Parecer CNE/CP 009/2001, aprovado em 08/05/2001.)

BRASIL. Ministério da Educação. Secretaria de Educação Média e Tecnológica. Parâmetros Curriculares Nacionais: ensino médio: bases legais. Brasília, 1999b, 188p. Www.mec.gov.br

FLAVELL, J. H. (1976). Metacognitive aspectes of problem solving. In: L. B. Resnick. (Ed) The nature of intelligence. pp. 231-35. Hildale, NJ: Lawrence Erbauem. Citado por Souza e Fávero (2002).

FOUREZ, G. et al. Alfabetización científica y tecnológica: acerca de las finalidades de la enseñanza de las ciencias. Buenos Aires: Colihues S.R.L., 1997.

FREIRE, P. Pedagogia da Autonomia: saberes necessários à prática educativa. $13^{a}$ ed. São Paulo: Paz e Terra, 1999.

Pedagogia do Oprimido. 14 a . ed. Rio de Janeiro: Paz e Terra, 1985.

1983.

Educação como Prática da Liberdade. 18 a . ed. Rio de Janeiro: Paz e Terra,

MAIA VIDAL, E. Investigação sobre domínios da alfabetização científica e tecnológica em escolas cearenses. In: Vianna, D. M.; Peduzzi, L. O. Q.; Borges, O. N.; Nardi, R. 
(Orgs.). Atas do VIII Encontro de Pesquisa em Ensino de Física. São Paulo: SBF, 2002. (CD-Rom, arquivo: CO71.pdf).

PADCT. Informe PADCT Nos. 01, 02, 03, 04. Secretaria Executiva do PADCT. SeplanCNPq. Brasília - DF. Abril a Dezembro. 1984.

PARENTE, A. (org.) Imagem-máquina: a era das tecnologias do virtual. Trad. Rogério Luz et al, Rio de Janeiro: Ed. 34, 1993, 304 p.

POSTMAN, N. Tecnopólio: a rendição da cultura à tecnologia. Trad. Reinaldo Guarany. São Paulo: Nobel, 1994.

SOUZA, Carlos Alberto. Investigação-Ação Escolar e Resolução de Problemas de Física: o potencial dos meios tecnológico-comunicativos. Florianópolis, SC. 2004. 316p. Tese (Doutorado em Educação) - Programa de Pós-graduação em Educação, Universidade Federal de Santa Catarina.

ZANETIC, J. Física e arte: uma ponte entre duas culturas. In: Vianna, D. M.; Peduzzi, L. O. Q.; Borges, O. N.; Nardi, R. (Orgs.). Atas do VIII Encontro de Pesquisa em Ensino de Física. São Paulo: SBF, 2002. (CD-Rom, arquivo: COCD1_1.pdf). 